\title{
Research on Business Model Design of Patent Entrepreneurship in Digital Environment
}

\author{
Lan Ding* \\ Guangxi University of Science and Technology \\ Liuzhou, China \\ 1666836443@qq.com
}

\author{
Zhaohui Chen \\ Guangxi University of Science and Technology \\ Liuzhou, China
}

\begin{abstract}
This paper studies the business model design of patent entrepreneurship in a digital environment. Starting from the connotation and characteristics of patents and entrepreneurship, the paper analyzes the impact of patent characteristics and entrepreneurial activity characteristics on business model design. The business model design model of patent entrepreneurship in the digital environment is constructed from the three dimensions of resources, strategy and environment. The key resources in business model design mainly include: patents, complementary assets, and entrepreneurial teams; the strategic level mainly involves the cost leadership strategy and the differentiation strategy of enterprises; environmental factors include government policies and digital enabling are two key elements. The innovation of this paper is to analyze the role of digital in the process of enterprise value creation and acquisition, in order to provide suggestions for enterprises to innovate their own business model.
\end{abstract}

Keywords-digital environment; patent entrepreneurship; business model design; innovation performance

\section{INTRODUCTION}

The transformation of patent achievements and the realization of patent value are the important impetus for the implementation of China's innovation-driven development strategy. Since the 18th National Congress of the CPC, China has issued a series of policies to promote the construction of entrepreneurial innovation platforms, and to encourage entrepreneurship innovation through the creation and application of intellectual property rights. Over the past five years, there have been more than 4200 new ventures, more than 3600 technology business incubators and more than 400 accelerators in China, and independent innovation and Entrepreneurship Based on patents has become a new trend. As one of the most common forms of commercialization of patent technology, patent entrepreneurship plays an important role in promoting economic development and enterprise value creation in China. However, in reality, most technology start-ups fail because they neglect the role of business model, which leads to the failure of entrepreneurship because input can't be successfully converted into output.

In the digital economy, the intensification of market competition and the shortening of innovation cycle of technology have increased the difficulty of patent entrepreneurship, making it difficult to obtain entrepreneurial resources and the formulation of entrepreneurial strategies increasingly complex and vague. How should enterprises design their business models matching their own patent technological characteristics to enhance the efficiency of integration of entrepreneurial resources and formulations of entrepreneurial strategies in order to improve innovation performance? It is a problem that needs to be paid attention to at present. The existing research on the impact of digitalization on business model design is not perfect, and less from the perspective of patent transformation. From the perspective of patent entrepreneurship, this paper will discuss the relationship among patent entrepreneurship, digitization and business model design, focusing on the analysis of the impact of patent entrepreneurship and digitization on business model design, providing a reference path for business model design of patent entrepreneurship in the digital environment, and enriching relevant research.

\section{Business Model Design of PATENT ENTREPRENEURSHIP IN DIGITAL ENVIRONMENT}

\section{A. The connotation of patent Entrepreneurship}

The earliest research on entrepreneurship focused on "trait research", focusing on individual entrepreneurs, believing that entrepreneurship is "starting a new business from scratch". Schumpeter believes that innovation comes from entrepreneurship, which includes innovation and new technology, and regards entrepreneurs as creative destroyers. With the continuous integration and development of entrepreneurship theory and other multi-disciplines, entrepreneurship research at the enterprise level has gradually become the mainstream. Enterprise-level entrepreneurship research mainly involves two important concepts: corporate entrepreneurship and entrepreneurship orientation [1]. Corporate entrepreneurship refers to the process in which entrepreneurs or entrepreneurship teams create new enterprises, implement strategic renewal and innovation within the enterprise, reflecting an internal organizational process of established enterprises, which mainly includes three activities: innovation, venture capitals and strategic renewal[2]. Entrepreneurship orientation is an enterprise tendency that engages in risk, innovative, initiative and competitive and enterprising behavior. It mainly includes three dimensions: innovation, risk-taking and advanced action.

As the unity of innovation and monopoly, patent has the characteristics of technology, economy, exclusivity, regionality and time. According to the relevant theory of entrepreneurship, patent entrepreneurship can be a process of starting a new enterprise from scratch by individuals or groups relying on 
patents. It can also be the development of new enterprises and businesses at the enterprise level, including two dimensions of entrepreneurship orientation and corporate entrepreneurship. At the company level, patent entrepreneurship mainly refers to the activities of individuals or groups related to existing enterprises to create new business organizations and carry out innovation and renewal of strategy within the enterprise. Through the innovation and introduction of new products, new production processes, new organizational systems, entering new business areas or changing business scope, they can expand their scale of operation in existing or new markets, and through the patent strategy. Full excavation of value and economic value can realize the new value. Entrepreneurship opportunities, resources and environments are the three key elements of entrepreneurship. As an important branch of entrepreneurship theory, the entrepreneurship strategy also plays a key role in the process of patent entrepreneurship [3].

Government policies have an important impact on patent entrepreneurship. At the beginning of entrepreneurship, enterprises lack the funds needed for commercialization, research and development results are highly uncertain, and the risk of technological innovation is high, which hinders the innovation and development of enterprises to a certain extent. Government subsidies, tax relief for high-tech enterprises, $R \& D$ tax relief policies and so on can make enterprises out of the "valley of death" at the beginning of entrepreneurship, and provide continuous financial incentive support in the process of entrepreneurship to ensure the leap from growth to maturity of enterprises.

\section{B. Business model design}

The essence of business model is to define the way in which enterprises provide value to customers, attract customers to pay value, and convert these payments into profits. Therefore, it reflects management's assumptions about what customers want, what they want, and how enterprises organize to best meet these needs and get paid and profitable from them. Current definitions of business models can be divided into four categories: economic, operational, strategic and integrated. The definition of integration class is a summary of the first three definitions. The business model describes how an enterprise locates and integrates a series of variables with internal relevance in strategic direction, operational structure and economic logic, so as to facilitate the establishment of a sustainable competitive advantage in a specific market. Business model design is a series of activities designed by enterprises to capture business opportunities and create value [4]. Design and implementation of business model matching with new technology are the necessary condition for successful commercialization of enterprise patent technology. The business model mainly consists of four parts: customer interface, the core strategy, the strategic resources and value network. The core resources and the core strategy are the key elements of patent entrepreneurship. The core strategy mainly includes the enterprise's business purpose, product and market scope, the differentiation basis and so on, while the strategic resources mainly include the core competitiveness, the strategic assets and the core processes.

\section{The impact of patent entrepreneurship on business model design}

The impact of patent entrepreneurship on business model design is mainly embodied in two dimensions: one is the impact of entrepreneurial characteristics on business model design; the other is the impact of patent characteristics on business model design (Fig. 1). The process of entrepreneurs developing creative ideas into mature business models is the evolution of the elements and structures of the model, and also the process of entrepreneurship. The business model has a life cycle, which should include the standardization period, the consolidation period, the adaptation period, the revision period and the reconstruction period. The business model of enterprises will evolve from the basic level to the specific level and the rule level. Moreover, with the change of enterprise environment, effective business model must face adjustment. It needs to be clear that business model design is the overall change of the enterprise system, which seeks to be different in the future competitive environment, rather than simply technological innovation or product innovation [5]. The construction of business model is a dynamic process emerging gradually in the process of entrepreneurship, not through planning. It requires entrepreneurs to constantly test the elements or structure of a viable business model.

The characteristic of the patent is the core element that distinguishes patent entrepreneurship from non-patent entrepreneurship. As a kind of intellectual property rights, the most basic and distinct feature of the patent is "exclusivity"[6]. The patent monopoly refers to the patent holder's exclusive right to manufacture, use, sell and import his invention and creation. The patent monopoly is mainly embodied in three aspects: technological monopoly, legal monopoly and strategic monopoly. The technology monopoly is mainly reflected in the impact on the bargaining power of enterprises. The stronger the patent monopoly power is, the stronger the bargaining power of enterprises is. Legal monopoly refers to the protection of patentee's patent right by means of legal protection, which can integrate external technology, improve and enhance the advantages of existing products and obtain new market advantages for enterprises. Strategic monopoly originates from the curve of learning experience within the enterprise[7]. The main motivation is to spill over the core knowledge of the enterprise, so as to shorten the product development cycle, reduce the operating cost of the enterprise, and enhance the market share speed of the product.

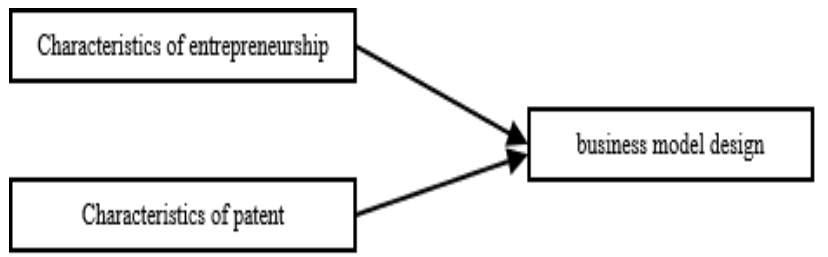

Fig. 1. The impact of patent entrepreneurship on business model design 


\section{Analysis of Business Model Design of Patent ENTREPRENEURSHIP}

\section{A. Analysis of the impact of digitalization on the business model of patent Entrepreneurship}

In the digital age, the key ability of patent entrepreneurship is to design and implement a business model with big data as its core. The progress of digital technology promotes the pursuit of new business values in five different but often overlapping modes: increasing products that generate data, digitizing assets, integrating intra-industry and cross-industry data, trading data and developing unique service capabilities. Increasing products that can generate data means that enterprises can collect data by introducing sensors, wireless communication, technology of big data into their products, and use the collected data to improve the design, operation, maintenance or repair of assets, or to enhance the execution of activities, which can significantly improve the innovation performance of enterprises. Asset digitalization refers to the conversion of non-monetary assets owned or controlled by enterprises into electronic data, which is a special way of asset allocation. We are familiar with the three Internet giants "BAT", "Drop-drop", "American League", "ofo" and so on. They all realize rapid circulation of asset and resource sharing by digitalizing assets, and achieve the effect of optimizing the resource allocation and reducing costs. Integrating intraindustry and cross-industry data means coordinating intraindustry and cross-industry information in a new way of big data integration, so as to reduce the waste of data resources and enhance the competitiveness of complementary assets of enterprises[8]. Data transaction under the background of digitalization enables enterprises to combine different data sets, optimize sales channels, etc., and increase enterprise income sources. Developing unique service capabilities means the automation of business processes by means of digitization. Data capabilities and assets within enterprises can be reoriented and transformed into self-sufficient businesses to enhance business profitability.

\section{B. Model construction of business model design of patent Entrepreneurship in Digital Environment}

On the basis of clarifying the connotation and relationship of patent entrepreneurship, the business model, digitalization, this paper argues that in the digital environment, the design of business model of patent entrepreneurship should be considered from three dimensions: entrepreneurial resources, entrepreneurial strategy and entrepreneurial environment. Among them, the entrepreneurship resources mainly include patents, complementary assets only, entrepreneurship team; entrepreneurship environment mainly includes government policies and digital enablement. Entrepreneurial resources will affect the enterprise's entrepreneurial strategy, and then the innovation performance, but also directly affect the innovation performance of the enterprise. Government policies and digital enablement will affect the patent entrepreneurship's entrepreneurial resources, entrepreneurial strategy and the innovation performance.

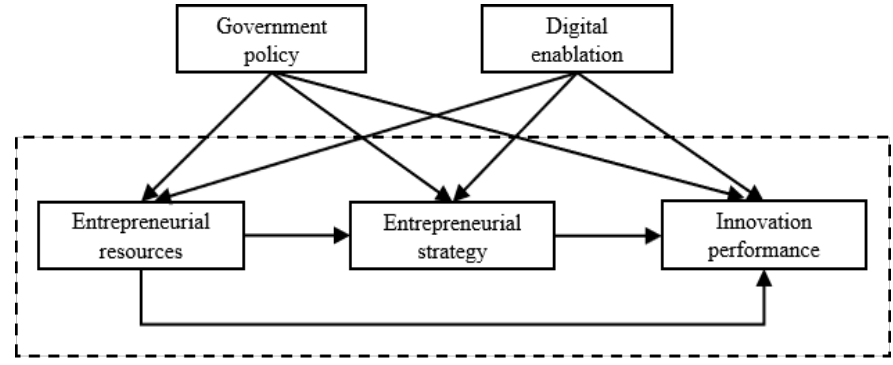

Fig. 2. Business model design of patent Entrepreneurship framework

\section{1) Entrepreneurial resources}

Entrepreneurial resources refer to the sum of all kinds of tangible and intangible resources used in the whole process of entrepreneurship in order to achieve the goal of entrepreneurship. There are three kinds of core resources for the patent entrepreneurship: patents, entrepreneurship team and complementary assets.

The patent monopoly is the most important factor affecting the entrepreneurship strategy and the innovation performance. The strength of monopoly will affect the choice of business strategies, and different business strategies will lead to different performance. In addition, breakthrough patents make it easier for enterprises to obtain the venture capital or pledge financing to ensure the operation and performance of enterprises. Complementary assets can be divided into manufacturing complementary assets, human complementary assets and market complementary assets. The status quo of complementary assets is different, the strategies adopted will also have an impact, and the innovation performance will be different[9]. The resource endowment of entrepreneurial team, such as previous work experience and the network relationship of society, can reduce enterprise cost, trial and error cost and learning cost. The market value and influence of entrepreneurship team members can enhance the visibility and overall image of enterprises, help to introduce core resources and obtain the venture capital, and broaden income sources.

\section{2) Entrepreneurial strategy}

Entrepreneurial strategy refers to the decision-making behavior of resource integration and allocation to achieve new value creation under uncertain internal and external environment. Entrepreneurial strategy can be divided into two categories: the cost-leading strategy and the differentiation strategy. The cost-leading strategy and the differentiation strategy in the entrepreneurship strategy have a significant role in promoting the enterprise performance. The more quickly and effective enterprises can formulate and implement these two strategies, the more significant they can improve the innovation performance. Compared to the cost-leading strategy, the differentiation strategy has a greater role in promoting entrepreneurship performance. The formulation of entrepreneurship strategy is closely related to the realization of the enterprise's competitive advantage, the improvement of its performance and its continuous development. The formulation of entrepreneurship strategy will be influenced by the core resources and external environment of the enterprise itself. Different choice of entrepreneurship strategy can explain the 
difference of performance of entrepreneurship to a certain extent.

\section{3) Entrepreneurial environment}

The government policy and digital enablement are extremely important for patent entrepreneurship. The government subsidy, especially $R \& D$ subsidy, can provide entrepreneurs with fast access to and accumulation of resources, reduce $R \& D$ costs, bring "cost effect" to enterprises, make up for the impact of $R \& D$ investment of the earlier stage on the capital chain, and maintain the development of enterprise innovation activities by providing strong financial support to entrepreneurs. Tax incentives can not only guarantee the normal development of R\&D activities, but also stimulate enthusiasm for innovation of entrepreneurs. Some tax subsidy incentive policies with restrictions and requirements can also urge enterprises to achieve the innovation performance, and promote technological innovation of the whole industry or industry. The application of digital technology in large patent data can help start-ups quickly and accurately grasp the characteristics of patent technology and patent distribution law, promote product innovation and value mining, enable enterprises to scientifically plan their own R\&D innovation and the patent layout, reduce the impact of patent litigation, invalid risk and so on on on entrepreneurial activities.

\section{CONCLUSION}

This paper mainly studies the business model design of patent entrepreneurship in digital environments. After research and analysis, this paper mainly draws the following conclusions and enlightenment:

- The monopoly of patents will affect the choice of business strategy of enterprises, and also affect the business strategy of enterprises. The background of the entrepreneurship team members determines their strengths and weaknesses in business model design to a certain extent. The core figures of the entrepreneurship team play a decisive role in the enterprise's value orientation and strategic planning. Complementary assets, especially proprietary complementary assets, will affect the efficiency of the implementation and execution of enterprise's entrepreneurship strategy, and determine whether the enterprise can achieve the acquisition of patent market value through value transmission and acquisition path.

- The formulation of entrepreneurship strategy is based on its own resources and competitive advantages. At the same time, it will be guided by government policies.
Business model design based on different strategies will have different impacts on the innovation performance of enterprises. Actively leading the strategic direction can create a first-mover advantage for start-ups, enabling start-ups to obtain market resources ahead of competitors and quickly gain the industry monopoly.

- To a certain extent, government policies determine the entrepreneurship strategy and technological route of enterprises. The higher the degree of coordination between policy orientation and enterprise development direction, the longer the enterprise development will be. Digital enablement is built on the capabilities of the big data of the enterprise. In the process of creating new value with digital platforms, we must pay attention to building strategy, technology facilities and analysis capabilities of the big data.

\section{ACKNOWLEDGMENT}

The National Natural Science Foundation of China (NSFC) project (71864005); Project of GuangXi philosophy and social science (13BJY015); Innovation Project of GuangXi University of Science and Technology (GKYC201716).

\section{REFERENCES}

[1] G. Covin, G Jeffrey, and G. T. Lumpkin. "Entrepreneurial Orientation Theory and Research: Reflections on a Needed Construct," Entrepreneurship Theory \& Practice. 2011, pp. 855-872.

[2] G. Crawford. P Christopher, and P. M. Kreiser. "Corporate entrepreneurship strategy: extending the integrative framework through the lens of complexity science," Small Business Economics. 2015, pp. 121.

[3] B. Demil and X. Lecocq. "Business Model Evolution: In Search of Dynamic Consistency," Long Range Planning. 2010, pp. 240-246.

[4] S. Trimi, and J. Berbegal-Mirabent. "Business model innovation in entrepreneurship," International Entrepreneurship \& Management Journal. 2012, pp. 449-465.

[5] H. Lin and M. Y. Wang. "Complementary assets, appropriability, and patent commercialization: Market sensing capability as a moderator," Asia Pacific Management Review. Mar 2015.

[6] D Emmanuel, et al. "Appropriability and Commercialization: Evidence from MIT Inventions," Management Science. 2008, pp. 884-893.

[7] Berman, J. Saul. "Digital transformation: opportunities to create new business models," Strategy \& Leadership. 2012, pp. 16-24.

[8] L. Colombo and H. Dawid. "Complementary assets, start-ups and incentives to innovate," International Journal of Industrial Organization.2016, pp. 177-190. 